\title{
Modeling the Parking Pricing of Multiple Parking Facilities under Different Operation Regimes
}

\author{
Wenbo Fan ${ }^{1,2}$, Muhammad Babar Khan ${ }^{3}$ \\ ${ }^{1}$ School of Transportation \& Logistics, Southwest Jiaotong University, Chengdu, China \\ ${ }^{2}$ Key Laboratory of Comprehensive Transportation of Sichuan Province, Chengdu, China \\ ${ }^{3}$ National Institute of Transportation, School of Civil \& Environmental Engineering, \\ National University of Sciences \& Technology, Islamabad, Pakistan \\ Email: fanwenbo@vip.126.com, babar-nit@nust.edu.pk
}

Received March 20, 2012; revised April 22, 2012; accepted May 16, 2012

\begin{abstract}
To explore the parking pricing of multiple parking facilities, this paper proposes a bi-level programming model, in which the interactions between parking operators and travelers are explicitly considered. The upper-level sub-model simulates the price decision-making behaviors of the parking operators whose objectives may vary under different operation regimes, such as monopoly market, oligopoly competition, and social optimum. The lower level represents a network equilibrium model that simulates how travelers choose modes, routes, and parking facilities. The proposed model is solved by a sensitivity based algorithm, and applied to a numerical experiment, in which three types of parking facilities are studied, i.e., the off-road parking lot, the curb parking lot, and the parking-and-ride (P \& R) facility. The results show in oligopoly market that the level of parking price reaches the lowest point, nonetheless the social welfare decreases to the lowest simultaneously; and the share of P \& R mode goes to the highest value, however the total network costs rise also to the highest. While the monopoly market and the social optimum regimes result in solutions of which P \& R facilities suffer negative profits and have to be subsidized.
\end{abstract}

Keywords: Parking Pricing; Operation Regimes; Bi-Level Programming; Multiple Parking Facilities; Network Equilibrium

\section{Introduction}

As one of the effective instruments of traffic demand management (TDM), parking pricing has been widely adopted by urban decision-makers around the world. The price level determines not only the profits of the parking operators, but also substantially influence travelers' choices on modes, routes, and parking facilities [1,2]. Traditional methods, which generally determine the optimal pricing by marginal cost pricing model [3,4], are not sufficient to assess these impacts on travelers' choices and subsequent variants of parking demand and network performance. Therefore, researchers applied network equilibrium model to study the parking pricing problem $[5,6]$. In addition, the emergence of park and ride $(P \& R)$ facilities as a new type of parking facility contributes more complexity to the situation, of which parking lots are located on the edge of urban area to encourage car drivers park and enter the city by public transport. Noticing the difference of the P \& R facility from pure parking facility, R. Garcia and A. Marin [7] firstly studied the parking pricing problem of the $\mathrm{P} \& \mathrm{R}$ facility, and established a continuous network design model. J. Y. T. Wang et al.
[8] proposed an integrated model for a linear city to determinate the pricing and siting issues of $\mathrm{P} \& \mathrm{R}$ facilities. Nonetheless, these works neglected the impacts of other types of parking facilities, e.g., off-road parking lot and curb parking in central business district (CBD), thus could not capture travelers' choices between various types of parking facilities. In addition, parking operators' behaviors are highly dependent on the operation regimes, such as monopolistic franchise, oligopolistic franchise, and government operation. Their operating objectives vary within different operation regimes, and lead to various competing behaviors. Such phenomenon have received some attentions, for instance, Z. C. Li et al. [9] studied the optimal fare structure of public transport under three operation regimes (i.e., monopoly market, oligopoly competition, and social optimum). They found that the operation regimes had significant influences on the optimal solutions. With respect to studies on parking issues, S.P. Anderson [10] made a comparative analysis on the paring pricing of government operation and private operation. The results showed that the private operation under free competition could lead to the lowest so- 
cial costs in total. J. F. Tsai and C. P. Chu [11] considered in parking pricing decision three types of players, i.e., the government, the operation corporation, and the customers, and established a three-stage Stachelberg game model to describe the interactions between these players. These existing valuable studies enriched our understanding about the parking pricing under different operation regimes, but had not yet explored the impacts of multiple parking facilities.

The objective of this paper is to model the parking pricing of multiple parking facilities under three operation regimes (i.e., the monopoly market, the oligopoly competition, and the social optimum). The following section presents several assumptions to facilitate the modeling. Section 3 formulates the pricing model with operators' objective functions under the three operation regimes. Section 4 discusses multimodal equilibrium model to represent the travelers' minimum travel disutility. A comprehensive solution algorithm is illustrated stepwise in Section 5, followed by numerical experiments. Finally, conclusive remarks are made along with recommendations for future researches.

\section{Assumptions and Variable Descriptions}

Given a multimodal network $G=(N, L)$, where $N$ is the set of all notes; $L$ is the set of all links. $G$ includes two sub-networks, the auto network $G_{a}=\left(N_{a}, L_{a}\right)$ and the metro network $G_{b}=\left(N_{b}, L_{b}\right)$. Without loss of generality, the following basic assumptions are made in this paper.

A1. There are two types of players in the network: parking operators and auto travelers. The operators make their pricing decisions based on the parking demand, which in turn varies as a result of travelers' adjustment to their journey costs.

A2. Consider three operation regimes: monopoly market, oligopoly competition, and social optimum; and three types of parking facilities: off-road parking lot, curb parking lot, and $\mathrm{P} \& \mathrm{R}$ facility.

A3. There are two modes for travelers to accomplish their journey, the automobile and the P \& R. For convenience of the following formulation, let " $a$ " and " $b$ " denote the two modes, and use the multinomial logit model to describe travelers' mode choice behaviors, which could fit the diversity in people's preferences.

A4. Suppose travelers are very familiar with the network, and make their travel decisions in a deterministic manner to minimize the travel disutility. Therefore, by competition the user equilibrium (UE) would reach.

A5. Introduce an elastic demand function to depict travelers' responses to various level of parking charges, such as switching the departure time, or even not making the journey.
Tables 1 and 2 present the parameters and variables that are used in the following model formulations.

\section{Parking Pricing Model}

\subsection{Profit Function}

The net profit $\Phi_{k}$ of operator $k$ can be formulated as the total revenue minus the operation costs,

$$
\Phi_{k}(\mathbf{z}, \mathbf{v}(\mathbf{z}))=\sum_{j \in J_{k}} z_{j} v_{j}-\sum_{j \in J_{k}}\left(H_{j}\left(C_{j}\right)+E_{j}\left(C_{j}\right)\right)
$$

where, the bold symbols represent the vectors of the corresponding variables. It is assumed that $H_{j}$ and $E_{j}$ are linear functions of the parking capacity $C_{j}$, in forms of $H_{j}\left(C_{j}\right)=\tau C_{j}$ and $E_{j}\left(C_{j}\right)=\eta_{0}+\eta_{1} C_{j}$.

\subsection{Objective Functions}

\subsubsection{Monopoly Market}

In the monopoly market, there should be a single authorized agent who is responsible for operating all parking facilities. The objective of the agent would be to maximize its total net profit by guiding all operators in the market. Given an elastic demand, the maximization is to find the optimal parking fees for each parking facilities, and can be expressed as follows.

$$
\text { (U1) } \max _{\mathbf{z}} \sum_{k} \Phi_{k}(\mathbf{z}, \mathbf{v}(\mathbf{z}))
$$

where the parking demand can be obtained from the lower-level equilibrium model (given in Section 3), and operator $k$ 's net profit $\Phi_{k}$ can be calculated by Equation (1).

\subsubsection{Oligopoly Competition}

The oligopoly competition in this paper refers to the situation, in which operators act independently and compete for their own profits. When the competitive equilibrium reaches, no operator could earn more profits by his own adjustment of the parking pricing. Thus, the oligopolistic equilibrium can be formulated as a Cournot-Nash game problem,

$$
\text { (U2) } \max _{\mathbf{z}^{k}} \Phi_{k}\left(\mathbf{z}^{k}, \mathbf{z}^{-k}, \mathbf{v}\left(\mathbf{z}^{k}, \mathbf{z}^{-k}\right)\right), \forall k \in K
$$

where, $\mathbf{z}^{k}$ represents operator $k$ 's pricing strategy for its parking facilities, and $\mathbf{z}^{-k}$ is the pricing strategy of other operators.

\subsubsection{Social Optimum}

The social optimum represents the common situation where all parking facilities are operated by the government, who provides the parking as a public service. Therefore, the operational objective is to maximize the total social welfare (SW), which is defined here as a sum of the consumer surplus and the producer surplus. The 
Table 1. Subscripts and parameters used in mathematical formulations.

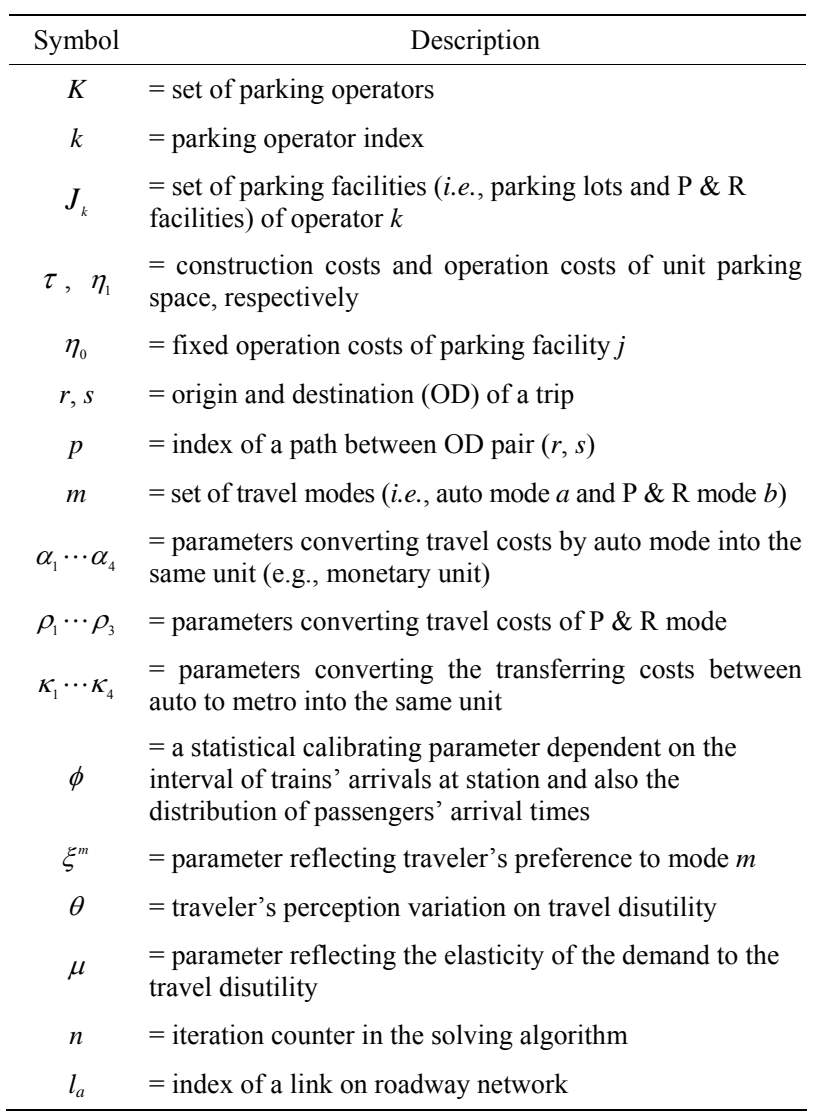

consumer surplus equals consumers' total utility minus their all disutility; and the producer surplus is the net profits of all operators. The objective function under the regime of social optimum can be given as,

$$
\text { (U3) } \begin{aligned}
\max \mathrm{SW} & =\left[\sum_{r, s} \int_{0}^{Q_{r s}} D_{r s}^{-1}(u) \mathrm{d} u-\sum_{r, s} \lambda_{r s} Q_{r s}\right] \\
& +\left[\sum_{k \in K} \Phi_{k}(\mathbf{z}, \mathbf{v}(\mathbf{z}))\right]
\end{aligned}
$$

where, the first part on the right-hand of Equation (4) is the consumer surplus; and the second part is the total net profits of all operators.

\section{Multimodal Equilibrium Model}

\subsection{Equilibrium Conditions}

According to the A4, travelers' behaviors satisfy the UE condition. That is to say, in the equilibrium state, the travel alternatives chosen by travelers have the minimum travel disutility. Such situation can be expressed as follows.

$$
U_{r s, j p}^{m}=\left\{\begin{array}{l}
=\lambda_{r s}^{m}, \text { if, } f_{r s, j p}^{m}>0 \\
\geq \lambda_{r s}^{m}, \text { if, } f_{r s, j p}^{m}=0
\end{array}\right\}
$$

\begin{tabular}{|c|c|}
\hline Symbol & Description \\
\hline$\Phi_{k}$ & $=$ net profit of operator $k$ \\
\hline$z_{j}, v_{j}$ & $=$ parking fee and demand of parking facility $j$ \\
\hline$H_{j}, E_{j}$ & $\begin{array}{l}=\text { construction costs and the operation costs of } \\
\text { parking facility } j, \text { respectively }\end{array}$ \\
\hline$C_{j}$ & $=$ parking capacity of parking facility $j$ \\
\hline$Q_{r s}$ & $=$ demand accommodated between $(r, s)$ \\
\hline$\lambda_{\text {rs }}$ & $=$ travel disutility between $(r, s)$ \\
\hline$D_{r s}^{-1}$ & $=$ inverse function of the elastic demand $Q_{r s}$ \\
\hline $\bar{Q}_{r s}$ & $=$ potential demand between $(r, s)$ \\
\hline$q_{r s}^{m}$ & $=$ travel demand by mode $m$ between $(r, s)$ \\
\hline$U_{r s, j p}^{m}, f_{r s, j p}^{m}$ & $\begin{array}{l}=\text { travel disutility and flow of mode } m \text { (i.e., } a \text { and } b) \\
\text { on route } p \text { via parking facility } j \text {, between OD pair }(r \text {, } \\
s)\end{array}$ \\
\hline$T_{r j, p}$ & $\begin{array}{l}=\text { actual travel time by auto from origin } r \text { via path } p \\
\text { to parking facility } j \text { nearby the destination } s\end{array}$ \\
\hline$\zeta_{j}$ & $=$ parking search time within parking facility $j$ \\
\hline$\gamma$ & $\begin{array}{l}=\text { average occupancy converting the parking fee into } \\
\text { per person }\end{array}$ \\
\hline$w_{j s}$ & $=$ walking time from parking lot $j$ to destination $s$ \\
\hline$T_{r j, p}^{1}$ & $\begin{array}{l}=\text { auto travel time from the origin } r \text { to the } \mathrm{P} \& \mathrm{R} \\
\text { facility } j \text { via path } p\end{array}$ \\
\hline$\varphi_{i j^{\prime}}$ & $=$ costs of transferring from automobile to metro \\
\hline$T_{j^{\prime} s, p}^{2}$ & $=$ in-vehicle time by metro \\
\hline$\Delta_{b}$ & $=$ additional penalty for the transferring \\
\hline$w_{i j^{\prime}}$ & $\begin{array}{l}=\text { walking time from } \mathrm{P} \& \mathrm{R} \text { facility } j \text { to the adjacent } \\
\text { metro station } j^{\prime}\end{array}$ \\
\hline$T_{j^{\prime}}^{w}$ & $=$ waiting time at station $j^{\prime}$ \\
\hline$F^{b}$ & $=$ dispatch frequency of the metro trains \\
\hline$\varepsilon$ & $=$ a pre-specified precision \\
\hline$t_{l_{a}}, \quad v_{l_{a}}$ & $=$ travel time and traffic flow on auto link $l_{a}$ \\
\hline$t_{l_{a}}^{0}, C_{l_{a}}$ & $=$ free-flow travel time and capacity on link $l_{a}$ \\
\hline$d_{j}^{0}$ & $=$ free-flow parking search time of parking facility $j$ \\
\hline
\end{tabular}

Table 2. Variables used in mathematical formulations.

where, the travel disutility functions of mode $a$ and $b$ are given as the following Equations (6) and (7), respectively.

$$
U_{r s, j p}^{a}=\alpha_{1} T_{r j, p}+\alpha_{2} \varsigma_{j}+\alpha_{3}\left(z_{j} / \gamma\right)+\alpha_{4} w_{j s}
$$

When the traveler chosen mode $b$ to travel from origin $r$ and park at $j$, and continue the journey by taking metro at station $j^{\prime}$ to destination $s$. Thus, his/her actual travel disutility can be given formulated as,

$$
U_{r s, j p}^{b}=\rho_{1} T_{r j, p}^{1}+\rho_{2} \varphi_{j j^{\prime}}+\rho_{3} T_{j^{\prime} s, p}^{2}+\Delta_{b}
$$

where, the transferring costs $\varphi_{i j^{\prime}}$ can be given as,

$$
\varphi_{j j^{\prime}}=\kappa_{1} \zeta_{j}+\kappa_{2}\left(z_{j} / \gamma\right)+\kappa_{3} w_{j j^{\prime}}+\kappa_{4} T_{j^{\prime}}^{w}
$$

where, the waiting time at station $j^{\prime} T_{j^{\prime}}^{w}$ can be calcu- 
lated by,

$$
T_{j^{\prime}}^{w}=\phi / F^{b}
$$

It is to be noted that passengers' arrival times is assumed to follow the normal distribution and the metro trains' interval time is constant. Then, following reference [1], it can be derived that $\phi=0.5$.

The traveler's choice model can be formulated according to the assumption A2 as,

$$
\begin{aligned}
& q_{r s}^{m} \\
& =Q_{r s} \exp \left(-\left(\xi^{m}+\theta \lambda_{r s}^{m}\right)\right) / \sum_{m} \exp \left(-\left(\xi^{m}+\theta \lambda_{r s}^{m}\right)\right)
\end{aligned}
$$

where, $Q_{r s}$ is supposed to be a continuous monotone decreasing function of the travel disutility between $(r, s)$, and is given in the following form:

$$
Q_{r s}=\bar{Q}_{r s} \exp \left(-\mu \lambda_{r s}\right)
$$

where, the travel disutility $\lambda_{r s}$, according to the nature of logit model, can be expressed by

$$
\lambda_{r s}=-\ln \left(\sum_{m} \exp \left(-\left(\xi^{m}+\theta \lambda_{r s}^{m}\right)\right)\right) / \theta .
$$

\subsection{Variational Inequality Model}

Following the work of W. H. K. Lam et al. [2] on network with multiple parking facilities, the aforementioned equilibrium conditions (Equations (5)-(11)) can be expressed as a variational inequality problem (of which the proof can be done by using Karush-Kuhn-Tucker conditions but omitted for brevity of this paper) as follows.

$$
\begin{aligned}
& \text { (L) } \sum_{r s} \sum_{m} \sum_{p, j} U_{r s, j p}^{m}\left(f_{r s, j p}^{m}-f_{r s, j p}^{m^{*}}\right) \\
& +\sum_{r s} \sum_{m} \frac{1}{\theta}\left(\ln \frac{q_{r s}^{m^{*}}}{Q_{r s}^{*}}+\xi^{m}\right)\left(q_{r s}^{m}-q_{r s}^{m^{*}}\right) \\
& -\sum_{r s} D_{r s}^{-1}\left(Q_{r s}^{*}\right)\left(Q_{r s}-Q_{r s}^{*}\right) \geq 0
\end{aligned}
$$

Subject to:

$$
\begin{gathered}
Q_{r s}=\sum_{m \in\{a, b\}} q_{r s}^{m} \\
q_{r s}^{a}=\sum_{p \in P_{r s, j}^{a}} f_{r s, j p}^{a} \\
q_{r s}^{b}=\sum_{p \in \in_{r s, j}^{b}} f_{r s, j p}^{b} \\
Q_{r s}, q_{r s}^{m}, f_{r s, j p}^{m} \geq 0
\end{gathered}
$$

where, $f_{r s, j p}^{m^{*}}, q_{r s}^{m^{*}}$, and $Q_{r s}^{*}$ represent the optimal solutions; the Equations (12)-(15) are demand conservation constraints for network and modes; Equation (16) is nonnegativity constraints for the OD demand, parking demand, and route flows.

\section{Solution Algorithm}

A sensitivity analysis based algorithm [12] is proposed in this section to solve equilibrium model. The fundamental logic is to convert the intractable non-linear problem into a quadratic programming problem by computing the decision variable's gradient information. The detailed stepwise procedure is given as follows:

Step 1. Initialization. Set an initial parking fee $\mathbf{z}^{0}$, and let the iteration counter $n=0$.

Step 2. Lower-level assignment. Substitute the given $\mathbf{z}^{n}$ into the lower-level problem, and calculate the equilibrium solution, and get the parking demand $\mathbf{v}^{n}$, the OD travel disutility $\lambda^{n}$, and the accommodated demand $\mathbf{Q}^{n}$.

Step 3. Sensitivity Analysis. Compute the equilibrium solution's gradient information with respect to the decision variable $\mathbf{z}$, and get $\partial \mathbf{v}(\mathbf{z}) / \partial \mathbf{z}, \partial \lambda / \partial \mathbf{z}$, and $\partial \mathbf{Q} / \partial \mathbf{z}$.

Step 4. Linearization. Linearize the parking demand $\mathbf{v}$, the OD travel disutility $\lambda$, and the accommodated demand $\mathbf{Q}$, and get the Equations (17)-(19).

$$
\begin{aligned}
& v_{j}(\mathbf{v}) \approx v_{j}\left(\mathbf{z}^{n}\right)+\sum_{j \in J_{k}}\left[\frac{\partial v_{j}(\mathbf{z})}{\partial z_{j}}\right]_{z_{j}=z_{j}^{n}}\left(z_{j}-z_{j}^{n}\right) \\
& Q_{r s}(\mathbf{z}) \approx Q_{r s}\left(\mathbf{z}^{n}\right)+\sum_{(r, s)}\left[\frac{\partial Q_{r s}(\mathbf{z})}{\partial z_{j}}\right]_{z_{j}=z_{j}^{n}}\left(z_{j}-z_{j}^{n}\right) \\
& \lambda_{r s}(\mathbf{z}) \approx \lambda_{r s}\left(\mathbf{z}^{n}\right)+\sum_{(r, s)}\left[\frac{\partial \lambda_{r s}(\mathbf{z})}{\partial z_{j}}\right]_{z_{j}=z_{j}^{n}}\left(z_{j}-z_{j}^{n}\right)
\end{aligned}
$$

Step 5. Substitute the above Equations (17)-(19) in to the upper-level objective function, and get a quadratic programming problem of variable $\mathbf{z}$, which can be solved by Newton methods. Yield an auxiliary solution $\mathbf{y}^{n}$.

Step 6. Update the parking fee by

$$
\mathbf{z}^{n+1}=\mathbf{z}^{n}+\left(\mathbf{y}^{n}-\mathbf{z}^{n}\right) / n .
$$

Step 7. Check convergence. If $\max \left|z_{j}^{n+1}-z_{j}^{n}\right| \leq \varepsilon$ stands, then stop and report the solution; otherwise, let $n=n+1$, and go to step 2 . The $\varepsilon$ is a pre-specified precision.

Remark. In step 2, the logit assignment can be undertaken by the Dial approach [13], and the deterministic network assignment can be preceded by the all-or-nothing approach [14] combined with Moore's shortest route algorithm [15].

\section{Numerical Experiments}

\subsection{Data Inputs}

This section presents a numerical experiment that is carried out with an illustrated network as shown in Figure 1. 


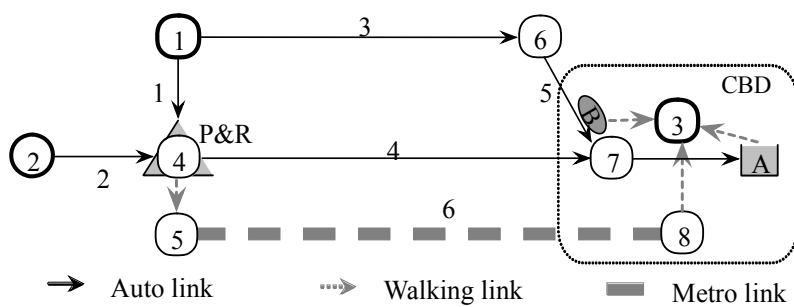

Figure 1. Illustration of the hypothetical network.

Node 1 and 2 represent two residential communities at suburban area; and note 3 denotes the central business district (CBD). There are three different-type parking facilities in the network: nodes $\mathrm{A}$ and $\mathrm{B}$ are an off-road parking lot and a curb parking lot within $\mathrm{CBD}$, respectively; near by node 4 is a P \& R facility.

Functions of the auto link travel time and the parking search time are given in the Bureau of Public Roads (BPR) form, $t_{l_{a}}\left(v_{l_{a}}\right)=t_{l_{a}}^{0}\left(1+0.15\left(v_{l_{a}} / C_{l_{a}}\right)^{4}\right)$ and $\zeta_{j}\left(v_{j}\right)=d_{j}^{0}+0.31\left(v_{j} / C_{j}\right)^{4.03}$. The involved parameters are specified with values as shown in Table 3.

To make the experiment representative, the values of all parameters are carefully designed. For this study, the metro fare is taken as $\$ 0.3 / \mathrm{km}$, the length of metro link is $30 \mathrm{~km}$, and the average speed on metro line is $60 \mathrm{~km} / \mathrm{h}$; The capacity of metro vehicle assumed is 300 passengers/carriage at the dispatching frequency of 6 carriages/hour. Other parameters include:

$\alpha_{1}=1.0, \quad \alpha_{2}=1.4, \quad \alpha_{3}=0.1, \alpha_{4}=1.8 ; \quad \rho_{1}=1.0$, $\rho_{2}=2.0, \quad \rho_{3}=1.0 ; \quad \kappa_{1}=0.7, \quad \kappa_{2}=0.1, \quad \kappa_{3}=0.9$; $\theta=1.0, \mu=0.7, \tau=10, \eta=0.09$, and $\gamma=1.0$. The transferring penalty for P \& R mode is set to be 0.1 . The potential demand of OD pair $(1,3)$ and $(2,3)$ are given to be 2000 persons/hour and 1000 persons/hour, respectively.

\subsection{Numerical Results}

The proposed algorithms are coded and implemented in Matlab on the Windows XP operating system, and the numerical experiments are conducted on a laptop with a Core2 Duo processor $2.4 \mathrm{GHz}$ processor and 2.0 GB RAM. Figures 2 and 3 reveal slice plots of the total profits and the social welfare with varying parking fees under the monopoly market regime and the social optimum regime, respectively. It is shown that the parking pricing could lead to positive, neutral, and negative objectives. The highest profit (\$3403.6, vid. Table 4) is reached in the monopoly market, when the parking fees are $\$ 15, \$ 13$, and $\$ 7$ for the curb parking, off-road parking lot, and P \& $\mathrm{R}$ facility, respectively (vid. Table 5). The highest social welfare (\$4012.4, vid. Table 4) is realized in the social optimum regime with parking fees being $\$ 13, \$ 11$, and \$6 (vid. Table 5).

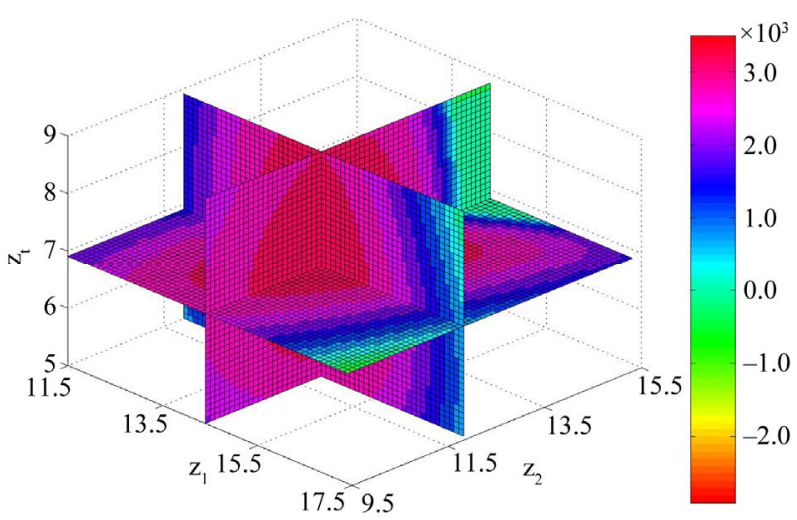

Figure 2. The total profit of the monopoly market.

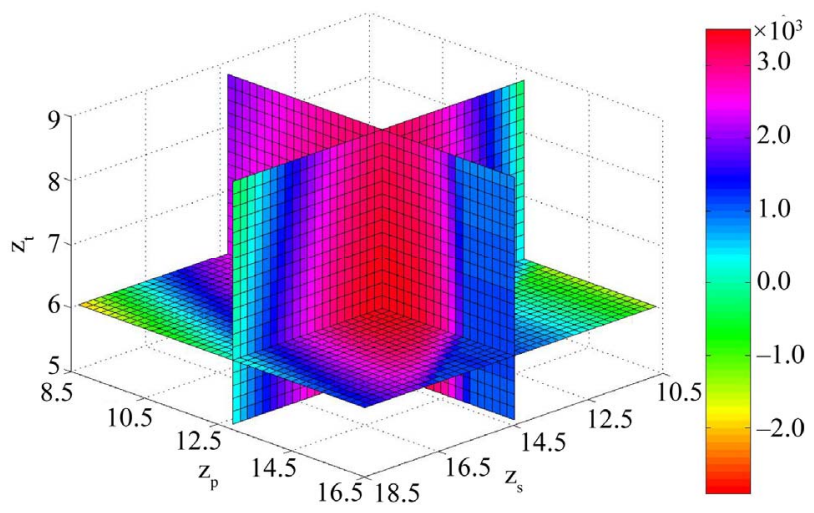

Figure 3. The social welfare of the social optimum regime.

Table 3. Parameters of the link travel time function and the parking search function.

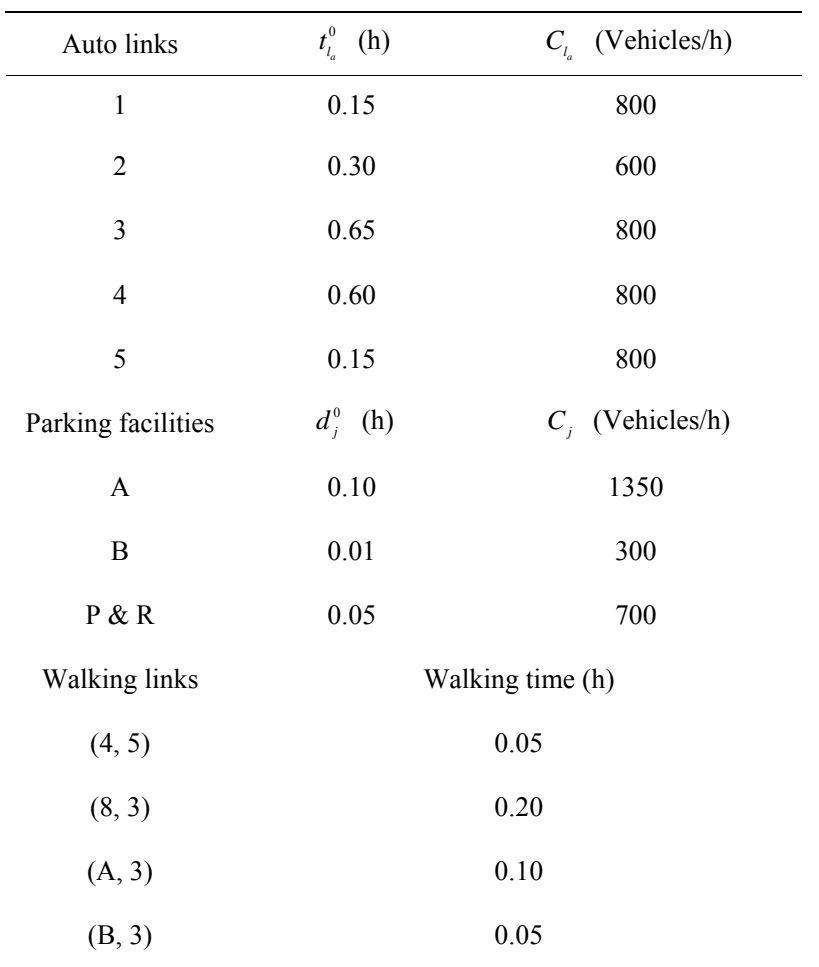


Table 4. The network performance under three regimes (\$).

\begin{tabular}{cccc}
\hline Regimes & Total profits & Social welfare & Network costs \\
\hline $\begin{array}{c}\text { Monopoly } \\
\text { market }\end{array}$ & 3403.6 & 3967.7 & 1252.8 \\
$\begin{array}{c}\text { Oligopoly } \\
\text { competition }\end{array}$ & 2095.9 & 3155.7 & 1734.7 \\
Social optimum & 3351.5 & 4012.4 & 1362.8 \\
\hline
\end{tabular}

Table 5. The optimal pricing and corresponding profits of three parking facilities (\$).

\begin{tabular}{ccccccc}
\hline \multirow{2}{*}{ Regimes } & \multicolumn{2}{c}{ Curb parking } & \multicolumn{2}{c}{ Off-road parking } & \multicolumn{2}{c}{ P \& R facilities } \\
\cline { 2 - 7 } & $\begin{array}{c}\text { Parking } \\
\text { fees }\end{array}$ & Profits & $\begin{array}{c}\text { Parking } \\
\text { fees }\end{array}$ & Profits & $\begin{array}{c}\text { Parking } \\
\text { fees }\end{array}$ & Profits \\
\hline $\begin{array}{c}\text { Monopoly } \\
\text { market }\end{array}$ & 15 & 2877 & 13 & 872.6 & 7 & -345 \\
$\begin{array}{c}\text { Oligopoly } \\
\text { competition } \\
\text { Social } \\
\text { optimum }\end{array}$ & 6 & 1189 & 5 & 854.6 & 5 & 52.5 \\
\hline
\end{tabular}

Table 5 shows the optimal pricing solution and the corresponding profits of three parking facilities. It can be found that the monopoly market yields the highest level of parking fee, while the oligopoly competition results in the lowest level. In addition, both the monopoly market and the social optimum maximize the overall objective at cost of the P \& R operator's loss, which means subsidies for P \& R operation should be necessary.

Table 4 presents the comparison of the three regimes in terms of total profits, social welfare, and network costs. In the view of parking operators, the monopoly market allow them obtain the highest profits; from the point of public administration, the social optimum regime results in the highest social welfare. Interestingly, the oligopoly competition yields positive profits for each operator, nonetheless the lowest profits and social welfare in total. Furthermore, the highest network costs emerge in the oligopoly competition in spite of more auto travelers are induced to choose the P \& R mode $(17.74 \%$, vid. Table 6). To this result, the explanation can be found in Table 6, which shows that the most demand is accommodated on the network under the oligopoly competition regime. Consequently, although the average travel costs decrease to the least of all ( $\$ 2.05 /$ person), the total network costs rise $(\$ 1734.7)$.

The aforementioned analyses show that operation regimes have significant influence on the optimal pricing solution, the operators' profits, the demand split, and also the overall network performance. It is believed in this paper that the least level of pricing is due to interactive competitions between the three parking facilities.

\section{Conclusions}

This paper explores the optimal pricing of three-type
Table 6. The equilibrium solution under three regimes.

\begin{tabular}{ccccc}
\hline Regimes & $\begin{array}{c}\text { Curb } \\
\text { parking }\end{array}$ & $\begin{array}{c}\text { Off-road } \\
\text { parking }\end{array}$ & P \& R facility & $\begin{array}{c}\text { Accommodated } \\
\text { demand (person) }\end{array}$ \\
\hline $\begin{array}{c}\text { Monopoly } \\
\text { market }\end{array}$ & $47.71 \%$ & $37.92 \%$ & $14.37 \%$ & 451 \\
$\begin{array}{c}\text { Oligopoly } \\
\text { competition }\end{array}$ & $30.25 \%$ & $52.01 \%$ & $17.74 \%$ & 848 \\
$\begin{array}{c}\text { Social } \\
\text { optimum }\end{array}$ & $40.81 \%$ & $44.71 \%$ & $14.48 \%$ & 528 \\
\hline
\end{tabular}

parking facilities under three operation regimes (i.e., monopoly market, oligopoly competition, and social optimum). To handle the interactions between pricing decision and parking demand, we propose a bi-level programming model simulating the decision-making of parking operators and auto travelers, simultaneously. In the upper level, operators optimize the parking pricing to achieve certain objectives, which may differ with the operation regimes; the lower-level sub-model is the network equilibrium, where travelers choose the best travel alternative according to parking fee, metro fare, travel time, walking time, etc. In the light of the complexity of the proposed non-linear model, a sensitivity analysis based algorithm is adopted. A numerical experiment is designed to assess the proposed model. The results verify that operation regimes play an influential role on the pricing decisions and the final outcomes. It is to be mentioned that parking operators' competition under the oligopoly regime decreases the overall level of pricing, attracts more demand, and promotes the share of the P \& R mode. These phenomena remind our policy-makers should carefully design the operation regimes to adjust the interests of multiple parking operators and mass travelers.

Our further researches will address important issues to relax the constraints made in this study. For instance, travelers' information about the network is not perfect, and the network is uncertain due to some random incidents, such as signal failure, road construction, and accidents. Interesting results are expected in evaluating the impacts of network uncertainty under different regimes.

\section{Acknowledgements}

The research is supported by National Natural Science Foundation of China (No. 51178403, 51108391).

\section{REFERENCES}

[1] Z. C. Li, H. J. Huang, W. H. K. Lam and S. C. Wong, "Optimization Of Time-Varying Parking Charges and Parking Supply in Networks with Multiple User Classes and Multiple Parking Facilities," Tsinghua Science and Technology, Vol. 12, No. 2, 2007, pp. 167-177. doi:10.1016/S1007-0214(07)70024-X

[2] W. H. K. Lam, Z. C. Li, H. J. Huang and S. C. Wong, 
"Modeling Time-Dependent Travel Choice Problems in Road Networks with Multiple User Classes and Multiple Parking Facilities," Transportation Research Part B, Vol. 40, No. 5, 2006, pp. 368-395. doi:10.1016/j.trb.2005.05.003

[3] A. Glazer and E. Niskanen, "Parking Fees and Congestion," Regional Science and Urban Economics, Vol. 22, No. 2, 1992, pp. 123-132. doi:10.1016/0166-0462(92)90028-Y

[4] E. Verhoef, P. Nijkamp and P. Rietveld, "The Economics of Regulatory Parking Polices: The (IM) Posssibilities of Parking Policies in Traffic Regulation," Transportation Research Part A, Vol. 29, No. 2, 1995, pp. 141-156. doi:10.1016/0965-8564(94)E0014-Z

[5] Z. Y. Mei, J. Chen and W. Wang, "Curb Parking Pricing Method Based on Parking Choice Behavior," Journal of Southeast University (English Edition), Vol. 22, No. 4, 2006, pp. 559-563.

[6] S. Carrese, S. Gori and T. Picano, "A Parking Equilibrium Model for Park Pricing and Park \& Ride Planning," Transportation Systems, Vol. 3, No. 6, 1997, pp. 12351239.

[7] R. Garcia and A. Marin, "Parking Capacity and Pricing in Park'n Ride Trips: A Continuous Equilibrium Network Design Problem," Annals of Operations Research, Vol. 116, No. 1-4, 2002, pp. 153-178. doi:10.1023/A:1021332414941

[8] J. Y. T. Wang, H. Yang and R. Lindsey, "Locating and Pricing Park-and-Ride Facilities in a Linear Monocentric
City with Deterministic Mode Choice," Transportation Research Part B, Vol. 38, No. 8, 2004, pp. 709-731. doi:10.1016/j.trb.2003.10.002

[9] Z. C. Li, W. H. K. Lam and S. C. Wong, "The Optimal Transit Fare Structure under Different Market Regimes with Uncertainty in the Network," Networks and Spatial Economics, Vol. 9, No. 2, 2008, pp. 191-216. doi:10.1007/s11067-007-9058-z

[10] S. P. Anderson and A. D. Palma, "The Economics of Pricing Parking," Journal of Urban Economics, Vol. 55, 2004, pp. 1-20. doi:10.1016/j.jue.2003.06.004

[11] J. F. Tsai and C. P. Chu, "Economic Analysis of Collecting Parking Fees by a Private Firm," Transportation Research Part A, Vol. 40, No. 8, 2006, pp. 690-697. doi:10.1016/j.tra.2005.12.001

[12] H. Yang, "Sensitivity Analysis for the Elastic-Demand Network Equilibrium Problem with Applications," Transportation Research B, Vol. 31, No. 2, 1997, pp. 55-70. doi:10.1016/S0191-2615(96)00015-X

[13] R. B. Dial, "A Probabilistic Multipath Traffic Assignment Algorithm Which Obviates Path Enumeration," Transportation Research, Vol. 5, 1971, pp. 83-111. doi:10.1016/0041-1647(71)90012-8

[14] Y. Sheffi, "Urban Transportation Networks: Equilibrium Analysis with Mathematical Programming Methods," Prentice-Hall, Englewood Cliffs, 1985.

[15] E. F. Moore, "The Shortest Path through a Maze," Harvard University Press, Cambridge, 1957. 